\title{
Ultrastructural and Immunological Characterization of Hepatitis C Core Protein-DNA Plasmid Complexes
}

\author{
${ }^{1}$ Nelson Acosta-Rivero, ${ }^{1}$ Yaraima Aguilera, ${ }^{1}$ Viviana Falcon, ${ }^{1}$ Joanna Poutou, ${ }^{1}$ Alexis Musacchio \\ ${ }^{1}$ Liz Alvarez-Lajonchere, ${ }^{1}$ Ivis Guerra, ${ }^{1}$ Julio C. Alvarez-Obregón, ${ }^{1}$ Yalena Amador-Cañizares \\ ${ }^{1}$ Gillian Martinez-Donato, ${ }^{1}$ Jeny Marante, ${ }^{1}$ Julio C. Aguilar, ${ }^{2}$ Yordanka Soria, ${ }^{1}$ Felix Alvarez \\ ${ }^{1}$ Angel Perez, ${ }^{1}$ Maria C. de la Rosa, ${ }^{1}$ Juan Morales, ${ }^{3}$ Juan B. Kouri and ${ }^{1}$ Santiago Dueñas-Carrera \\ ${ }^{1}$ Biomedicine Division, ${ }^{2}$ Bioterio Department, Center for Genetic Engineering and Biotechnology \\ P.O. Box 6162, C.P. 10600, C. Habana, Cuba \\ ${ }^{3}$ Centro de Investigación y de Estudios Avanzados (CINVESTAV-IPN), México City, México
}

\begin{abstract}
Recently, it has been shown that a truncated $\mathrm{HCV}$ core $(\mathrm{HCcAg})$ variant, covering the first 120 aa (HCcAg.120), interacts with plasmid DNA vaccine (pIDKE2), encoding the HCV structural proteins (HCcAg, E1 and E2). In the present work, HCcAg.120-pIDKE2 complexes, forming heterogeneous packaged structures, were visualized using a negative stain/rotary shadow technique. Interestingly, 72 hours after intramuscular injection of HCcAg.120-pIDKE2 complexes in Balb/c mice, E2 protein was immunolabeled in muscle cells. In fact, HCcAg.120-pIDKE2 complexes induced antiHCV humoral and cellular immune responses in mice when inoculated by both, parenteral or mucosal routes, although intranasal administration generally rendered weaker results. On the other hand, data demonstrated that Alum enhanced the $\mathrm{HCV}$-specific IgG antibody production. However, the analysis of the HCV-specific cellular immune response showed that HCcAg.120-pIDKE2 delivered in PBS by the intramuscular route induced the strongest $\mathrm{HCV}$-specific lymphoproliferative response, especially against E1 and induced viremia control in a vaccinia virus surrogate challenge model. These results support the use of HCcAg.120-pIDKE2 complexes in the rational design of therapeutic or preventive vaccine strategies against $\mathrm{HCV}$ infection.
\end{abstract}

Key words: Hepatitis C virus, Core antigen, DNA vaccine, immune response

\section{INTRODUCTION}

Hepatitis $\mathrm{C}$ virus (HCV) infection is considered a major health problem affecting an estimated 170 million people worldwide ${ }^{[1]}$. Approximately 50 to $80 \%$ of HCV patients develop chronic hepatitis, which may be complicated by cirrhosis and/or hepatocellular carcinoma ${ }^{[1]}$. At present, there is no vaccine available to prevent $\mathrm{HCV}$ infection and current therapies are not optimal $^{[2]}$. Thus, prophylactic and therapeutic approaches to prevent liver damage caused by $\mathrm{HCV}$ infection are urgently needed.

$\mathrm{HCV}$ is a member of the Flaviviridae family with a positive strand RNA of $9.6 \mathrm{~kb}^{[3]}$. The viral genome is translated into a single polyprotein of 3,000 amino acids in host cells. A combination of host and viral proteases are involved in polyprotein processing to give at least nine different proteins ${ }^{[4,5]}$. The structural proteins of $\mathrm{HCV}$ are believed to comprise the core protein $(\mathrm{HCcAg})$ and two envelope glycoproteins: E1 and $\mathrm{E} 2^{[5]}$.

Because $\mathrm{HCV}$ is an enveloped virus, neutralizing determinants likely reside on the surface of the envelope. The envelope protein E2 of HCV contains highly variable sequences within the $\mathrm{N}$-terminal region (HVR1), which are thought to contain neutralizing Bcell epitopes ${ }^{[6,7]}$. However, the role of neutralizing Abs in protective immunity against $\mathrm{HCV}$ infection is still uncertain $^{[6]}$.

Studies in humans and chimpanzees have indicated that failure to generate multispecific cellular immune responses against $\mathrm{HCV}$ in the acute phase of infection is associated with chronicity ${ }^{[8,9]}$. Conversely, patients with strong $\mathrm{HCV}$-specific cellular immune responses have lower levels of viremia and these responses correlate with recovery ${ }^{[10-12]}$. Of the cellular immune responses, the induction of Th1 type response, which has been linked to viral clearance in HCV, is probably important for a $\mathrm{HCV}$ vaccine ${ }^{[13]}$. Therefore, an ideal $\mathrm{HCV}$ vaccine may need to induce strong humoral responses against the envelope proteins and to prime broad HCV-specific T helper (Th) and cytotoxic T lymphocytes (CTL) responses ${ }^{[14]}$.

Previously, it has been reported that a recombinant C-terminal truncated $\mathrm{HCcAg}$ ( $\mathrm{HCcAg} .120)$ interacts in vitro with a plasmid DNA vaccine (pIDKE2) leading to

Corresponding Author:

Santiago Dueñas-Carrera, Biomedicine Division, Center for Genetic Engineering and Biotechnology, Ave. 31 e/ 158 y 190, P. O. Box 6162, C.P. 10 600, La Habana, Cuba, Tel: (53 7) 271 4764, Fax: (53 7) 2714764 
heterogenous virus-like particles (VLPs) formation ${ }^{[15]}$. In addition, HCcAg. 120 has recently been shown to enhance the immune response elicited by pIDKE2 plasmid co-delivered in Balb/c mice ${ }^{[16]}$. In the present study, HCcAg.120-pIDKE2 complexes were characterized at the ultrastructural level. Besides, novel elements about the immunogenicity of these proteinDNA complexes, including the influence of adjuvant and administration route are described.

\section{MATERIALS AND METHODS}

Antigens and antibody: Endotoxin-free HCcAg. 120 was produced for research use only up to $90 \%$ of purity as previously described ${ }^{[17]}$. Recombinant truncated E1 (E1.339) and E2 (E2.680) proteins have been previously described ${ }^{[18,19]}$. Particulate recombinant small surface antigen of hepatitis B virus (HBsAg) was produced with more than $95 \%$ of purity at the CIGB production facilities (CIGB, Cuba $)^{[20]}$. A mouse monoclonal antibody against the residues 580-600 of E2 (mAb SS-HepC.3) was used to detect E2.680 in immunoelectron microscopy experiments ${ }^{[21]}$.

Plasmids: pIDKE2 ${ }^{[22]}$ is a plasmid for DNA immunization containing the gene-fragment coding for the first 650 aa of the HCV polyprotein (including HCcAg, E1 and E2). pAEC-K6 plasmid $^{[22]}$ was used as negative control.

Vaccinia viruses and cell lines: The recombinant vaccinia virus vvRE, that expresses aa 1-650 of HCV polyprotein, is a vaccinia virus derived from the Western Reserve (WR) strain of vaccinia virus ${ }^{[23]}$. African green monkey kidney cells BSC-40 ${ }^{[24]}$ were grown in Dulbecco's modified Eagle's medium (DMEM) supplemented with $10 \%$ FBS and were used for determination of vaccinia virus titer in mice ovaries.

HCcAg.120-pIDKE2 plasmid interaction: In vitro protein-nucleic acid assembly reactions were carried out using conditions previously described ${ }^{[15]}$. Briefly, 5 $\mu \mathrm{g}$ of purified HCcAg.120 was mixed with an equal volume of pIDKE2 plasmid $(50 \mu \mathrm{g})$. The reactions were incubated at $30{ }^{\circ} \mathrm{C}$ for $10 \mathrm{~min}$ followed by $15 \mathrm{~min}$ on ice.

Transmission electron microscopy (TEM): Either pIDKE2 plasmid or HCcAg.120-pIDKE2 complexes were processed for TEM using a negative stain/rotary shadow technique. Fifteen microliter drops of freshly prepared samples were placed on glow-discharged collodion/carbon-coated 400-mesh copper grids for 3 min. The solution was wicked off with filter paper and grids were rinsed in double-distilled $\mathrm{H} 2 \mathrm{O}$ and allowed to dry. Rotary shadowing was performed using $1 \mathrm{in}$. of 0.008 -inch $\mathrm{Pt} / \mathrm{Pd} 80 / 20$ wire at $12^{\circ}$ angle. Grids were imaged in a Jeol JEM 2000EX electron microscope operated at $80 \mathrm{kV}$.

Immunoelectron microscopy (IEM): The muscle tissue samples were fixed with $4 \% \quad(\mathrm{v} / \mathrm{v})$ paraformaldehyde containing $0.2 \%(\mathrm{v} / \mathrm{v})$ glutaraldehyde in $0.1 \mathrm{M}$ phosphate buffer $(\mathrm{pH} 7.3)$ at $4{ }^{\circ} \mathrm{C}$ for $3 \mathrm{~h}$ and washed with $0.1 \mathrm{M}$ phosphate buffer. Fixed cells were dehydrated as previously described ${ }^{[21]}$, embedded in Lowicryl and polymerized by exposure to ultraviolet light at room temperature for $72 \mathrm{~h}$. Ultrathin sections of liver biopsies were incubated with anti-E2 $\mathrm{mAb}$ in phosphate buffer, for $45 \mathrm{~min}$ at RT. The sections were rinsed three times for $30 \mathrm{~min}$ at RT with $0.1 \% \mathrm{BSA}$ in PBS (BSA-PBS) and incubated for $1 \mathrm{~h}$ at RT with goldlabeled anti-mouse IgG (Amersham, England) diluted 1:100 in BSA-PBS. As control, the primary antibody was substituted by normal mouse serum. All sections were stained with saturated uranyl acetate and lead citrate and examined with a JEOL/JEM 2000 EX transmission electron microscope (JEOL, Japan).

Immunization schedule: HCcAg.120-pIDKE2 complexes were used to induce specific immune responses in mice. On one hand, four groups of ten female Balb/c mice (6 to 8 weeks old) each, were immunized either intramuscularly (i.m.) or intranasal (i.n.) as follow: Group 1 was i.m. immunized with HCcAg.120-pIDKE2 $(5 \mu \mathrm{g}$ of HCcAg.120/50 $\mu \mathrm{g}$ of pIDKE2) in phosphate-buffered saline (PBS) solution $\left(0.1 \mathrm{M} \mathrm{NaCl}, 2 \mathrm{mM} \mathrm{KCl}, 10 \mathrm{mM} \mathrm{Na} \mathrm{HPO}_{4}, 1 \mathrm{mM}\right.$ $\mathrm{KH}_{2} \mathrm{PO}_{4} \mathrm{pH}$ 7.4), Group 2 was i.m. immunized with HCcAg.120-pIDKE2 adsorbed to Aluminum Hydroxide (Alum), Group 3 was i.n. immunized with HCcAg.120-pIDKE2 in PBS, Group 4 was i.m. immunized with $50 \mu \mathrm{g}$ of pAEC-K6 absorbed in Aluminum Hydroxide. All groups were boosted at 14 and 28 days after primary immunization. Serum samples were taken before immunization and on day 42 by retro-orbital punction. Splenocytes from 5 mice per group were isolated on day 42. Five animals per group received two additional doses of the respective immunogen at weeks 6 and 12 after primary immunization. These mice were challenged with a recombinant vaccinia virus expressing HCV Core, E1 and $\mathrm{E} 2$ proteins, 2 weeks after the last immunization.

Enzyme-linked immunosorbent assay (ELISA): The 96-well microtiter plates (Costar, Cambridge, MA) were coated with $100 \mu \mathrm{L}$ of either E1.339 $\left(10 \mu \mathrm{g} \mathrm{mL}^{-1}\right)$ or E2.680 $\left(10 \mu \mathrm{g} \mathrm{mL}^{-1}\right)$ diluted in coating buffer (50 $\mathrm{mM}$ carbonate buffer, $\mathrm{pH} 9.6)$ at $4^{\circ} \mathrm{C}$ overnight. After three washes with PBS containing $0.05 \%$ Tween 20 (PBST), the wells were blocked with $100 \mu \mathrm{l}$ of PBST containing $1 \%$ skim milk at room temperature for 1 hour. Each well received $100 \mu l$ of the mice sera in PBST at serial two-fold dilutions (starting from 1:50) and the plates were incubated at $37^{\circ} \mathrm{C}$ for 1 hour. 
Subsequent steps were performed as previously described $^{[22]}$. The cut off value to consider a sample as positive was established as twice the mean absorbance (O.D) value of control mice sera (animals inoculated with pAEC-K6 absorbed in Alum) from three determinations. Antibody titer was considered as the maximal serum sample dilution rendering a positive reaction in ELISA.

Lymphoproliferation assay: This assay has been described previously ${ }^{[25]}$. Briefly, pools of spleen cells from five immunized mice per group were cultivated in triplicate by using 96 -well round-bottom plates at $2 \times 10^{5}$ cells per well in $200 \mu \mathrm{l}$ of RPMI-1640 containing $10 \%$ heat-inactivated fetal calf serum (FCS), $2 \mathrm{mmol} \mathrm{L}^{-1} \mathrm{~L}-$ glutamine, 50 units $\mathrm{mL}^{-1}$ penicillin and $50 \mu \mathrm{g} \mathrm{mL}^{-1}$ streptomycin. Cells were stimulated with $5 \mu \mathrm{g} \mathrm{mL}{ }^{-1}$ of either E1.339 or E2.680 in triplicate. As negative controls, effector cells were stimulated with either recombinant $\mathrm{HBsAg}$ or medium alone. Concanavalin A $\left(5 \mu \mathrm{g} \mathrm{mL}^{-1}\right.$ ) was used as positive control. After stimulation for 5 days, $\left[{ }^{3} \mathrm{H}\right]$ thymidine was added (1 $\mu \mathrm{Ci} /$ well). Cells were incubated for an additional 6 hours and the $\left[{ }^{3} \mathrm{H}\right]$ thymidine incorporation into DNA was measured after harvesting the plates. Lymphocyte stimulation index (SI) was calculated as the mean counts per minute (cpm) measured after antigen stimulation divided by the mean cpm of cells incubated with medium alone. A SI of $>3$ was considered as positive. Splenocytes from unimmunized mice were analyzed as controls and they all showed a SI of $<1.5$.

Vaccinia virus titer in the ovaries of challenged mice: At 15 days after the final protein-DNA complexes administration, mice (5 per group) were challenged intraperitoneally with $10^{6}$ plate forming units (pfu) of vaccinia virus expressing $\mathrm{HCV}$ structural proteins (vvRE). Five days after the challenge, mice were sacrificed and the ovaries were removed, homogenized, sonicated and assayed for viral titer by serial 10-fold dilutions on a plate of BSC-40 indicator cells. After 2 days of culture, the medium was removed, the BSC-40 cell monolayer was stained with $1 \%$ crystal violet (Merck, Darmstadt, Germany) for $10 \mathrm{~min}$ and the number of plaques per well was counted.

Statistical procedures: To compare differences among groups, a One-way ANOVA with the Newman-Keuls post-test or Kruskal-Wallis non-parametric statistic test with Dunn's Multiple Comparison Test as post-test were used. $\mathrm{P}<0.05$ was considered significant.

\section{RESULTS}

TEM characterization of HCcAg.120-pIDKE2 complexes: Either pIDKE2 plasmid (arrowheads) or HCcAg.120-pIDKE2 complexes (arrows) were visualized in TEM using the negative stain/rotary shadow technique (Fig. 1). HCcAg.120-pIDKE2 complexes forming heterogeneous packaged structures were observed (Fig. 1, arrow). The size ranged between $80 \mathrm{~nm}$ and $300 \mathrm{~nm}$.

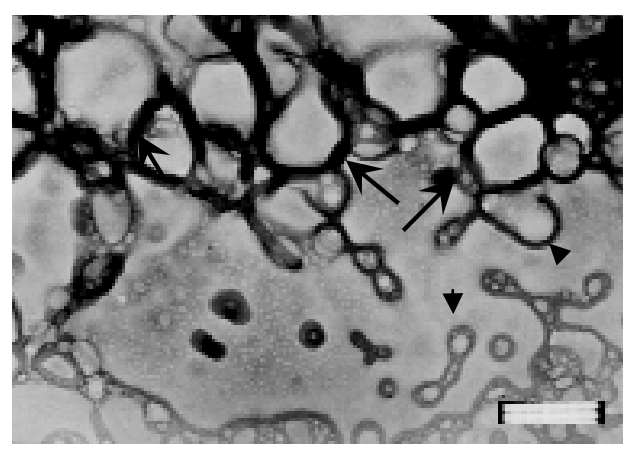

Fig. 1: Transmission electron microscopy image of HCcAg.120-pIDKE2 complexes using rotary shadowing technique. Arrows: HCcAg.120pIDKE2 complexes, arrowhead: pIDKE2 plasmid. (Bar=200 nm)

TEM characterization of $\mathrm{HCV}$ expression: HCV expressing cells are shown in Fig. 2. Seventy-two hours after inoculation of HCcAg.120-pIDKE2, E2 protein was immunolabeled in muscle cells. In addition, VLPs were rarely observed. These particles were scarcely detected and immunolabeled with anti-E2 antibodies (Fig. 2B, arrows). No immunolabeling was observed in muscle cells from non-immunized mice (Fig. 2A).

Effect of the administration route and adjuvant on the immunogenicity of HCcAg.120-pIDKE2 complexes: To evaluate the effect of the immunization route and adjuvant on the immunogenicity of HCcAg.120-pIDKE2 in mice, HCcAg.120-pIDKE2 either in PBS or in Alum were i.m. or i.n. injected into $\mathrm{Balb} / \mathrm{c}$ mice. Particularly, we focused on the immune response elicited against envelope antigens, since it is only generated after protein production occurs in vivo in cells incorporating functional pIDKE2 molecules.

Total serum envelope-specific IgG response: Presence of anti-envelope antibodies (against E1 and E2) in immunized mice was detected by an antienvelope ELISA. The HCcAg.120-pIDKE2/Alum formulation induced the highest anti-E1 and anti-E2 IgG responses (Fig. 3). These responses showed significant differences compared to that detected in mice immunized with HCcAg.120-pIDKE2/PBS by the i.n. route. However, no significant differences were observed with respect to the group immunized with HCcAg.120-pIDKE2/PBS by the i.m. route (Fig. 3).

Envelope-specific lymphoproliferative responses: Strong anti-envelope proliferative responses were detected in splenocytes from all mice immunized with HCcAg.120-pIDKE2 (Fig. 4). 

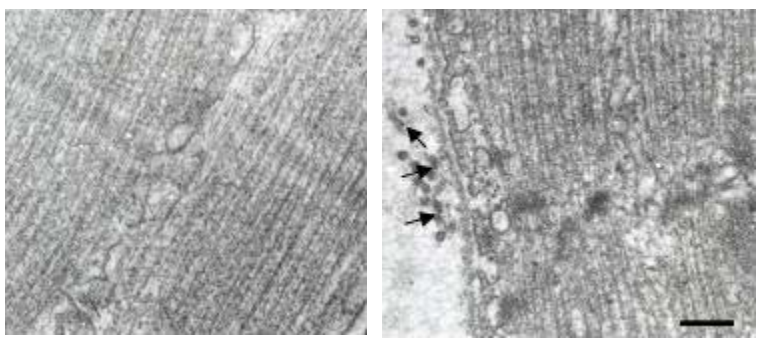

Fig. 2: Immunolabeling of E2 by IEM. A) Muscle cells from non-immunized mice, no immunostaining was observed using anti-E2 mAbs. B) Immunostaining with anti-E2 mAbs and gold-labeled anti-mouse $\mathrm{IgG}$, detected $\mathrm{E} 2$ in muscle cells and VLPs. $(\mathrm{Bar}=200 \mathrm{~nm})$

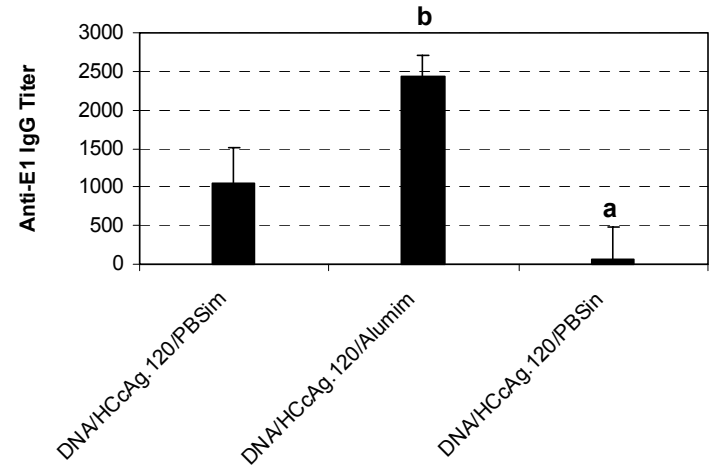

A

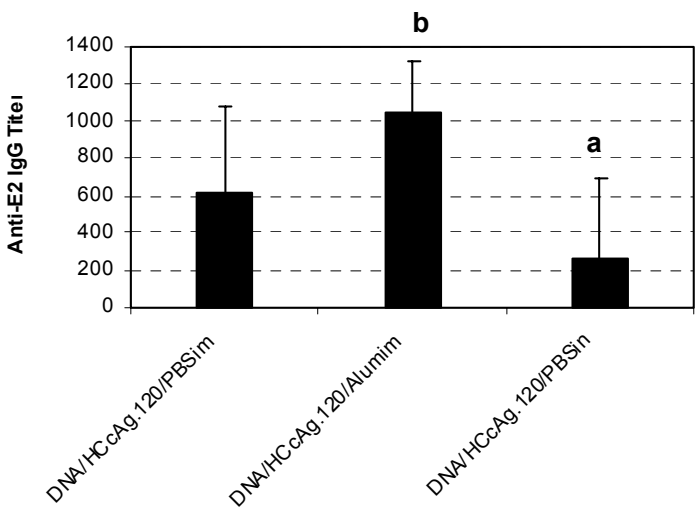

B

Fig. 3:Induction of humoral immune response by injection of HCcAg.120-pIDKE2 into Balb/c mice. Titters of either total E1-specific IgG (A) $[\mathrm{b}>\mathrm{a} * *,(* * \mathrm{p}<0.01)]$ or total E2-specific IgG (B) $[\mathrm{b}>\mathrm{a} * *,(* * \mathrm{p}<0.01)]$ response in sera of mice after immunization are shown. DNA: pIDKE2 plasmid; im: intramuscularly; in: intranasally. Results are shown as the reciprocal of the serum dilution equivalent to twice the mean optical density (O.D.492 nm) of negative control. Errors bars indicating the standard errors of the means are shown. Stat: ** Kruskal-Wallis nonparametric statistic test with Dunn's Multiple Comparison Test as post-test were used. $\mathrm{P}<0.05$ was considered significant
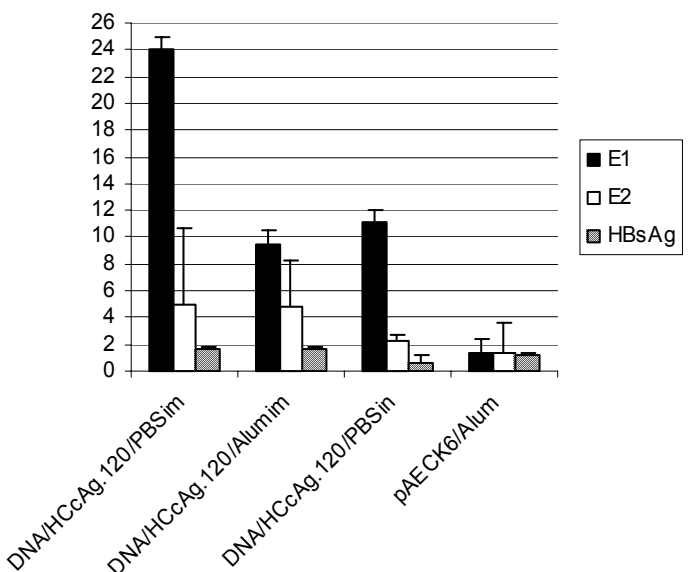

Fig. 4:Proliferative responses of splenic lymphocytes from immunized mice. DNA: pIDKE2 plasmid; im: intramuscularly; in: intranasally. Data are shown as the mean SI. Errors bars indicating the standard errors of the means are shown. SI of $\geq 3$ is considered positive. Groups are indicated on the $\mathrm{x}$-axis

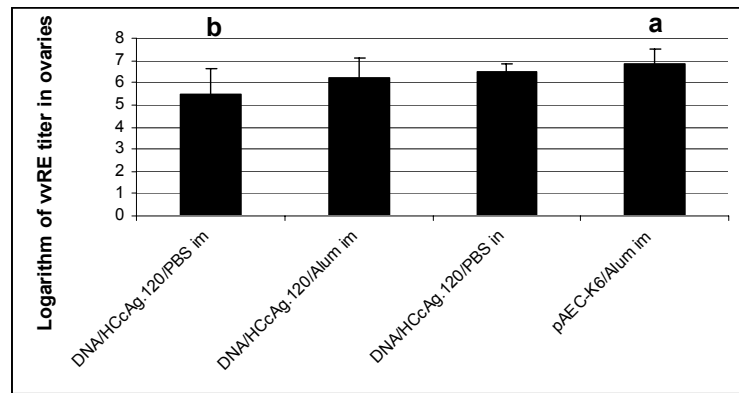

Fig. 5: Viremia control in a surrogate vaccinia virus challenge model. Results are shown as the mean logarithm of vvRE, a vaccinia virus expressing $\mathrm{HCV}$ structural antigens, in ovaries of immunized mice. Error bars indicate the standard deviation of the mean from 5 individual mice. Stat: * One-way ANOVA with the NewmanKeuls post-test were used. $\mathrm{P}<0.05$ was considered significant. $\mathrm{b}<\mathrm{a} * *,(* * \mathrm{p}<0.01)$

Note that there was a trend for the anti-E1 proliferative response to be higher than the anti-E2 proliferative response in all groups of immunized mice. In mice immunized with HCcAg.120-pIDKE2/PBS by the i.n. route, anti-E1 but not anti-E2 proliferative responses were detected. Remarkably, the anti-E1 proliferative response obtained in mice i.m. immunized with HCcAg.120-pIDKE2/PBS was at least two fold higher than that observed in the other groups of mice (Fig. 4).

Viremia control in a vaccinia virus surrogate challenge model: Two weeks after the final immunization, five animals per group were challenged with a recombinant vaccinia virus expressing the $\mathrm{HCV}$ structural proteins. Only the administration of 
HCcAg.120-pIDKE2/PBS by i.m. route could significantly contribute to viremia control in challenged mice (Fig. 5). Viral titer in ovaries of these mice was $1.5 \log$ lower $(\mathrm{p}<0.01)$ than the value detected in negative control animals (pAEC-K6/Alum group), although no statistical differences were observed with respect to groups immunized with HCcAg.120-pIDKE2 in Alum or administered in PBS by i.n route.

\section{DISCUSSION}

Recently, it has been shown that a truncated $\mathrm{HCcAg}$ variant, comprising the first 120 aa (HCcAg.120) of this antigen, with a 32 aa N-terminal fusion peptide (6xHistag-XpressTMepitope), interacts with nucleic acids ${ }^{[15]}$. In fact, in vitro interaction between HCcAg.120 and pIDKE2 plasmid has been previously demonstrated by delayed electrophoretic mobility. Formation of large and heterogenous VLPs, characterized by a buoyant density of $1.30-1.34 \mathrm{~g} \mathrm{~mL}^{-1}$, has been described ${ }^{[15]}$.

In the present study, HCcAg.120-pIDKE2 complexes were visualized by TEM, showing the rounded shape of these complexes. In addition, HCV expression in vivo was monitored by TEM. Immunolabeling of E2 indicates early expression of $\mathrm{HCV}$ proteins in muscle cells, after protein-DNA complexes inoculation in mice. Besides, VLPs with an average size of $40 \mathrm{~nm}$ were immunolabeled with antiE2 antibodies indicating the presence of E2 on the surface of such structures. However, it was very difficult to detect these particles, suggesting that the assembly process might be inefficient.

The HCV envelope proteins are believed to contain important epitopes ${ }^{[7]}$. Therefore, many studies have focused on the induction of anti-envelope humoral and cellular immune responses in mice and monkeys $^{[19,22,26,27]}$. Our data show that HCcAg.120pIDKE2 complexes were immunogenic in vivo, inducing strong anti-HCV humoral and $\mathrm{T}$ cell proliferative immune responses, directed against envelope antigens. This is in agreement with a previous work, showing that mixtures of HCcAg and pIDKE2 elicited stronger and more diverse humoral and cellular immunity than the immunization with the individual components in Balb/c mice ${ }^{[16]}$. This kind of mixture also controlled the infection after the challenge with a recombinant vaccinia virus expressing the $\mathrm{HCV}$ core ${ }^{[16]}$. In the present work, i.m injection of HCcAg.120pIDKE2 complexes induced viremia control after challenge with a recombinant vaccinia virus expressing HCV Core, E1 and E2.

It should be noted that HCcAg.120-pIDKE2 administration by the i.n. route showed a trend to be less immunogenic than inoculation of HCcAg.120pIDKE2 by the i.m. route. Probably, immune response against antigens encoded by pIDKE2 is not correctly activated in mucosa since a previous study has demonstrated that individual administration of HCcAg. 120 protein by the i.n. route induces strong immune responses in Balb/c mice ${ }^{[20]}$.

On the other hand, results shown here demonstrated that Alum enhanced the HCV-specific IgG antibody production after HCcAg.120-pIDKE2 administration in mice. However, the analysis of the HCV-specific cellular immune response showed that HCcAg.120-pIDKE2 complexes delivered in PBS by the i.m. route induced the strongest $\mathrm{HCV}$-specific lymphoproliferative response, especially against E1. This result might be suggesting that formulation of protein-DNA complexes in conjunction with Alum can not only enhance the specific anti-HCV antibody response, but also influence the bias of the immune response to a Th2 pattern. Previously, Kwissa et al. showed that a CTL response was not elicited when AlPO4 was used in formulations containing protein and a DNA vaccine ${ }^{[28]}$. This is consistent with the observed failure in controlling vaccinia virus infection, in the surrogate challenge model, after administration of HCcAg.120-pIDKE2 formulated in Alum, in contrast to inoculation in PBS. Indeed, several evidences indicate that in the vaccinia virus challenge model, protective response is mainly mediated by the cellular immune response induced against the antigen shared by the virus and the immunogen used ${ }^{[29-31]}$.

Several human studies have presented evidence that a strong $\mathrm{HCV}$-specific CD4+ $\mathrm{T}$ cell proliferative response is associated with either viral clearance in acute hepatitis $\mathrm{C}^{[32-34]}$ or in chronic HCV infection successfully treated with IFN $^{[35]}$ or with a benign carrier state ${ }^{[36,37]}$. The importance of HCV specific CD4+ T cell proliferative response in viral control has also been demonstrated in patients with $\mathrm{HCV}$ recurrence after loss of virus-specific $\mathrm{CD} 4+\mathrm{T}$ cell response ${ }^{[33]}$. In general, persons able to mount a strong cellular immune response are more likely to experience viral clearance $^{[13,37,38]}$. Therefore, our findings that HCcAg.120-pIDKE2 complexes can induce not only anti-HCV envelope antibodies, but strong cellular immunity, suggest their potential use as components of $\mathrm{HCV}$ vaccine candidates. Moreover, the ability of $\mathrm{HCV}$ Core protein for binding nucleic acids and forming protein-DNA complexes might be particularly useful for the development of DNA vaccine formulations against different pathogens.

\section{ACKNOWLEDGEMENTS}

The authors thank Dr. Rafael F. SanchezBetancourt, for critical reading of the manuscript and for many helpful suggestions.

\section{REFERENCES}

1. Alter, H.J. and M. Houghton, 2000. Nat.Med., 6: 1082-1086. 
2. Houghton, M., 2000. Curr. Top. Microbiol. Immunol., 242: 327-339.

3. Choo, Q.L., G. Kuo, A.J. Weiner, L.R. Overby, D.W. Bradley and M. Houghton, 1989. Science, 244: 359-362.

4. Grakoui, A., C. Wychowski, C. Lin, S.M. Feinstone and C.M. Rice, 1993. J. Virol., 67: 1385-1395.

5. Hijikata, M., N. Kato, Y. Ootsuyama, M. Nakagawa and K. Shimotohno, 1991. Proc. Natl. Acad. Sci., USA, 88: 5547-5551.

6. Farci, P., J. Bukh and R.H. Purcell, 1997. Springer Semin. Immunopathology, 19: 5-26.

7. Youn, J.W., S.H. Park, D. Lavillette, F.L. Cosset, S.H. Yang, C.G. Lee, H.T. Jin, C.M. Kim, M.T. Shata, D.H. Lee, W. Pfahler, A.M. Prince and Y.C. Sung, 2005. Hepatology, 42: 1429-1436.

8. Bassett, S.E., B. Guerra, K. Brasky, E. Miskovsky, M. Houghton, G.R. Klimpel and R.E. Lanford, 2001. Hepatology, 33: 1479-1487.

9. Ferrari, C., A. Valli, L. Galati, A. Penna, P. Scaccaglia, T. Giuberti, C. Schianchi, G. Missale, M.G. Marin and F. Fiaccadori, 1994. Hepatology, 19: 286-295.

10. Cooper, S., A.L. Erickson, E.J. Adams, J. Kansopon, A.J. Weiner, D.Y. Chien, M. Houghton, P. Parham and C.M. Walker, 1999. Immunity, 10: 439-449.

11. Rehermann, B., K.M. Chang, J.G. McHutchison, R. Kokka, M. Houghton and F.V. Chisari, 1996. J. Clin. Invest., 98: 1432-1440.

12. Thimme, R., D. Oldach, K.M. Chang, C. Steiger, S.C. Ray and F.V. Chisari, 2001. J. Exp. Med., 194: 13951406.

13. Lechner, F., D.K. Wong, P.R. Dunbar, R. Chapman, R.T. Chung, P. Dohrenwend, G. Robbins, R. Phillips, P. Klenerman and B.D. Walker, 2000. J. Exp. Med., 191: 1499-1512.

14. Liang, T.J., B. Rehermann, L.B. Seeff and J.H. Hoofnagle, 2000. Ann. Intern. Med., 132: 296-305.

15. Acosta-Rivero, N., J. Poutou, A. Mussachio, V. Falcon, Y. Aguilera, A. Rodriguez, A. Perez, J. Aguilar, M. de la Rosa, F. Alvarez, J. Morales-Grillo, J. Kouri and S. Dueñas-Carrera, 2005. Am. J. Infect. Dis., 1: 66-72.

16. Alvarez-Lajonchere, L., M. Gonzalez, J.C. AlvarezObregon, I. Guerra, A. Vina, N. Acosta-Rivero, A. Musacchio, J. Morales and S. Duenas-Carrera, 2006. Biotechnol. Appl. Biochem., 44: 9-17.

17. Acosta-Rivero, N., A. Rodriguez, A. Mussachio, J. Poutu, V. Falcon, D. Torres, J.C. Aguilar, M. Linares, M. Alonso, A. Perez, I. Menendez, J. Morales-Grillo, G. Marquez and S. Dueas-Carrera, 2005. Biochem. Biophys. Res. Commun., 334: 901-906.

18. Lorenzo, L.J., O. García, N. Acosta-Rivero, S. DueñasCarrera, G. Martínez, J.C. Alvarez-Obregón, D. Pichardo, A. Ramos, I. Guerra and J. Morales, 2000. Biotechnol. Appl. Biochem., 32: 137-143.

19. Martínez-Donato,G., Y. Capdesuñer, N. Acosta-Rivero, A. Rodríguez, J. Morales-Grillo, E. Martínez, M. González, J.C. Alvarez-Obregon and S. Dueñas-Carrera, 2005. Molecular Biotechnology. In press.

20. Aguilar, J.C., N. Acosta-Rivero, S. Dueas-Carrera, G.J. Morales, D. Pichardo, D. Urquiza, G. Guillen and V. Muzio, 2003. Biochem. Biophys. Res. Commun., 310: 59-63.
21. Falcon, V., N. Acosta-Rivero, G. Chinea, J. Gavilondo, M.C. de la Rosa, I. Menendez, S. Duenas-Carrera, A. Vina, W. Garcia, B. Gra, M. Noa, E. Reytor, M.T. Barcelo, F. Alvarez and J. Morales-Grillo, 2003. Biochem. Biophys. Res. Commun., 305: 1085-1090.

22. Duenas-Carrera, S., L. Alvarez-Lajonchere, J.C. Alvarez-Obregon, A. Perez, N. Acosta-Rivero, D.M. Vazquez, G. Martinez, A.Vina, D. Pichardo and J. Morales, 2002. Biotechnol. Appl. Biochem., 35: 205212.

23. Bronson, L.H. and R.F. Parker, 1941. J. Bacterol., 41: 56-57.

24. Brockman, W.W. and D. Nathans, 1974. Proc. Natl. Acad. Sci. USA, 71: 942-946.

25. Alvarez-Obregon, J.C., S. Duenas-Carrera, C. Valenzuela and J.M. Grillo, 2001. Vaccine, 19: 39403946.

26. Choo, Q.L., G. Kuo, R. Ralston, A. Weiner, D. Chien, G. Van Nest, J. Han, K. Berger, K. Thudium and C. Kuo, 1994. Proc. Natl. Acad. Sci.USA, 91: 1294-1298.

27. Duenas-Carrera, S., A. Vina, R. Martinez, L. AlvarezLajonchere, J.C. Alvarez-Obregon, J. Marante, A. Perez, O. Mosqueda, G. Martinez and J. Morales, 2004. Biotechnol. Appl. Biochem., 39: 249-255.

28. Kwissa, M., E.B. Lindblad, R. Schirmbeck and J. Reimann, 2003. J. Mol. Med., 81: 502-510.

29. Arribillaga, L., A.L. deCerio, P. Sarobe, N. Casares, M. Gorraiz, A. Vales, O. Bruna-Romero, F. Borras-Cuesta, G. Paranhos-Baccala, J. Prieto, J. Ruiz and J.J. Lasarte, 2002. Vaccine, 21: 202-210.

30. Murata, K., M. Lechmann, M. Qiao, T. Gunji, H.J. Alter and T.J. Liang, 2003. Proc. Natl. Acad. Sci. USA, 100: 6753-6758.

31. Doherty, P.C., W. Allan, D.B. Boyle, B.E. Coupar and M.E. Andrew, 1989. J. Infect. Dis., 159: 1119-1122.

32. Cramp, M.E., P. Carucci, S. Rossol, S. Chokshi, G. Maertens, R. Williams and N.V. Naoumov, 1999. Gut, 44: 424-429.

33. Gerlach, J.T., H.M. Diepolder, M.C. Jung, N.H. Gruener, W.W. Schraut, R. Zachoval, R. Hoffmann, C.A. Schirren, T. Santantonio and G.R. Pape, 1999. Gastroenterology, 117: 933-941.

34. Rosen, H.R., C. Miner, A.W. Sasaki, D.M. Lewinsohn, A.J. Conrad, A. Bakke, H.G. Bouwer and D.J. Hinrichs, 2002. Hepatology, 35: 190-198.

35. Cramp, M.E., S. Rossol, S. Chokshi, P. Carucci, R. Williams and N.V. Naoumov, 2000. Gastroenterology, 118: 346-355.

36. Missale, G., R. Bertoni, V. Lamonaca, A. Valli, M. Massari, C. Mori, M.G. Rumi, M. Houghton, F. Fiaccadori and C. Ferrari, 1996. J. Clin. Invest., 98: 706714.

37. Botarelli, P., M.R. Brunetto, M.A. Minutello, P. Calvo, D. Unutmaz, A.J. Weiner, Q.L. Choo, J.R. Shuster, G. Kuo and F. Bonino, 1993. Gastroenterology, 104: 580587.

38. Woitas, R.P., M. Lechmann, G. Jung, R. Kaiser, T. Sauerbruch and U. Spengler, 1997. J. Immunol., 159: 1012-1018. 